\title{
Microbiota: a Sword that Breaks Through Diabetes
}

\author{
Zhu Jiang Dai ${ }^{1 \#}$, Jing Qiu Zhang ${ }^{2 \#}$, Qi Wu ${ }^{1 \#}$, Hui Wen Fang ${ }^{1}$, Dong Tang ${ }^{2}$, Dao Rong Wang ${ }^{2}$ \\ ${ }^{1}$ Department of Clinical Medical College, Yangzhou University, Yangzhou 225001, Jiangsu, China, ${ }^{2}$ Department of General Surgery, \\ Institute of General Surgery, Clinical Medical College, Yangzhou University, Northern Jiangsu People’s Hospital, Yangzhou 225001, \\ Jiangsu, China
} \begin{abstract}
transplantation; Roux-En-Y gastric bypass; Sleeve gastrectomy
\section{Introduction}

Diabetes is a serious metabolic syndrome, and hyperglycemia is its main clinical symptom. The number of people with diabetes in China has risen sharply, which has brought a serious burden to China's economy and medical care system [1]. There are two types of diabetes. Type 1 diabetes is an autoimmune disease caused by the destruction of pancreatic $\beta$ cells. Type 2 diabetes is a metabolic disorder that is often associated with obesity and overweight [2]. The human intestinal microbiota, also known as the "hidden organ", participates in the body's metabolism [3]. The intestinal microbiota plays a vital role in food absorption and the development of low-grade inflammation [4], which are two key processes involved in the development of obesity and diabetes. A large number of clinical studies have shown that the behavior of the intestinal microbiota may lead to metabolic disorders in the human body, including diabetes and obesity. This review describes the relationship between the gut microbiota and diabetes, and discusses the potential mechanisms by which the gut microbiota is involved in the development of type 1 diabetes, obesity, and type 2 diabetes. Obtaining a better understanding of the intestinal microbiota should aid in the treatment or prevention of these metabolic disorders.
\end{abstract}

Abstract: Diabetes are a group of metabolic disorders characterized by persistent hyperglycemia that is a major public health problem. Middle-aged and elderly people are at the highest risk of type 2 diabetes, but younger cases are now being diagnosed with greater frequency. Numerous clinical studies have reported that the behavior of the intestinal microbiota may affect the development of metabolic disorders in humans, including obesity and diabetes. This review describes the relationship between the gut microbiota and diabetes, and discusses the possible mechanisms underlying their involvement in the development of type 1 diabetes, obesity, and type 2 diabetes. By better understanding the intestinal microbiota, it may become possible to treat diabetes and obesity by manipulating the gut microbes through probiotics and dietary changes, fecal microbiota transplantation, or surgical approaches.

Key words: Microbiota; Type 1 diabetes; Type 2 diabetes; Obesity; Inflammation; Probiotics; Fecal microbial

Zhu Jiang Dai, Jing Qiu Zhang and Qi Wu made an equal contribution to this paper.

${ }^{\#}$ Corresponding author: Dong Tang, MD, PhD, Department of General Surgery, Institute of General Surgery, Northern Jiangsu People's Hospital, Yangzhou, Clinical Medical College, Yangzhou University, Yangzhou 225001, Jiangsu, China; Tel: +86 1895278 3556; +86 514 8737 3395; Email: 83392785@qq.com; Dao Rong Wang, MD, PhD, Department of General Surgery, Institute of General Surgery, Northern Jiangsu People's Hospital, Yangzhou, Clinical Medical College, Yangzhou University, Yangzhou 225001, Jiangsu, China; Tel: +86 139 0525 2590; +86 5148737 3395; Email: daorong666@sina.com

\section{Intestinal Microbiota and Type 1 Diabetes}

Intestinal microbiota regulate the induction of type 1 diabetes under the influence of dietary factors, pH and gender

Type 1 diabetes is an autoimmune disease. Type 1 diabetes occurs when pancreatic $\beta$ cells (which produce insulin) are destroyed by self-reactive T cells. Although type 1 diabetes is primarily caused by genetic defects, epigenetic and environmental factors play an important role in the development of the disease. Type 1 diabetes is related to human leukocyte antigen (HLA) II genes. Methylation of HLA genes can modulate gene expression [5]. Interestingly, Nielsen DS et al. [6] found that intestinal microbiota plays an important role in the development of type 1 diabetes in animal models. They showed that segmented filamentous bacteria (SFB) strongly affected the development of the immune system in non-obese diabetic (NOD) mice, which affected Th cell maturation and induced intestinal Th17 (IL17 producing) cells [6]. SFB can promote IL-17-dependent immunity and autoimmune responses [7]. Wen L et al. [8] also demonstrated that NOD mice lacking the myeloid differentiation factor 88 (MyD88) protein, an adapter that recognizes microbial-stimulated innate immune receptors, did not develop type 1 diabetes. These studies suggest that changes in the gut microbiota are closely related to type 1 diabetes.

Changes in the intestinal environment can affect microbiota, thus affecting the occurrence of type 1 diabetes. The diet is a direct factor that influences both the microbiota and a variety of other risk factors (Figure 1). For example, a gluten-free (GLF) diet has been shown to have antidiabetic effects in mice, possibly by altering the immune function and the composition of the gut microbiota, which is considered to be an immune-related environmental factor 
[9] (Figure 1). However, the relationship between gluten and diabetes is not well understood. Marietta EV et al. [10] studied NOD mice and found that differences in gut microbiota could be attributed to gluten-containing (GLC) and GLF diets. Another study suggested that gluten can affect the development of diabetes by changing the number of immune cells or by altering the cytokine/chemokine expression patterns [11]. Frisk $\mathrm{G}$ et al. also found that type 1 diabetes was related to the length of exposure to gluten [12]. In addition, studies have shown that the intestinal microbiota has both positive and negative roles on gluten-induced immunopathology in mice [13]. Thus, once the microbial balance is disordered, it will lead to the occurrence of type 1 diabetes.

In addition to dietary factors, the intragastric $\mathrm{pH}$ and gender are related to the microbial activity. Studies have shown that the $\mathrm{pH}$ of drinking water affects the composition of the intestinal microbiota and the incidence of type 1 diabetes [14]. Markle and colleagues found that female nonobese diabetic (NOD) mice had a higher incidence of diabetes than male NOD mice under specific pathogen-free
(SPF) conditions. Surprisingly, if the mice were fed a glutenfree diet, these differences disappeared [15]. This suggests that the gender difference in type 1 diabetes sensitivity depends on the activity of the microbiota. In support of this, another study recently found that the intestinal microbiota was the determinant of adolescent diabetes [16]. This brings hope to patients with type 1 diabetes, and may be useful for preventing the development of type 1 diabetes.

\section{Inflammatory pathways by which microbiota induce type 1 diabetes}

As noted above, the intestinal microbiota are important in the development of type 1 diabetes through the interaction of MyD88 with the host innate immune system (Figure 1). Under SPF conditions, the MyD88 signaling pathway is required for the development of autoimmune diabetes in NOD mice. Knocking down MyD88 in NOD mice can prevent the occurrence of type 1 diabetes. Toll-like receptors (TLRs) are innate pattern recognition receptors involved in host defense, which interact with MyD88 to control symbiotic bacteria and maintain tissue integrity [17].

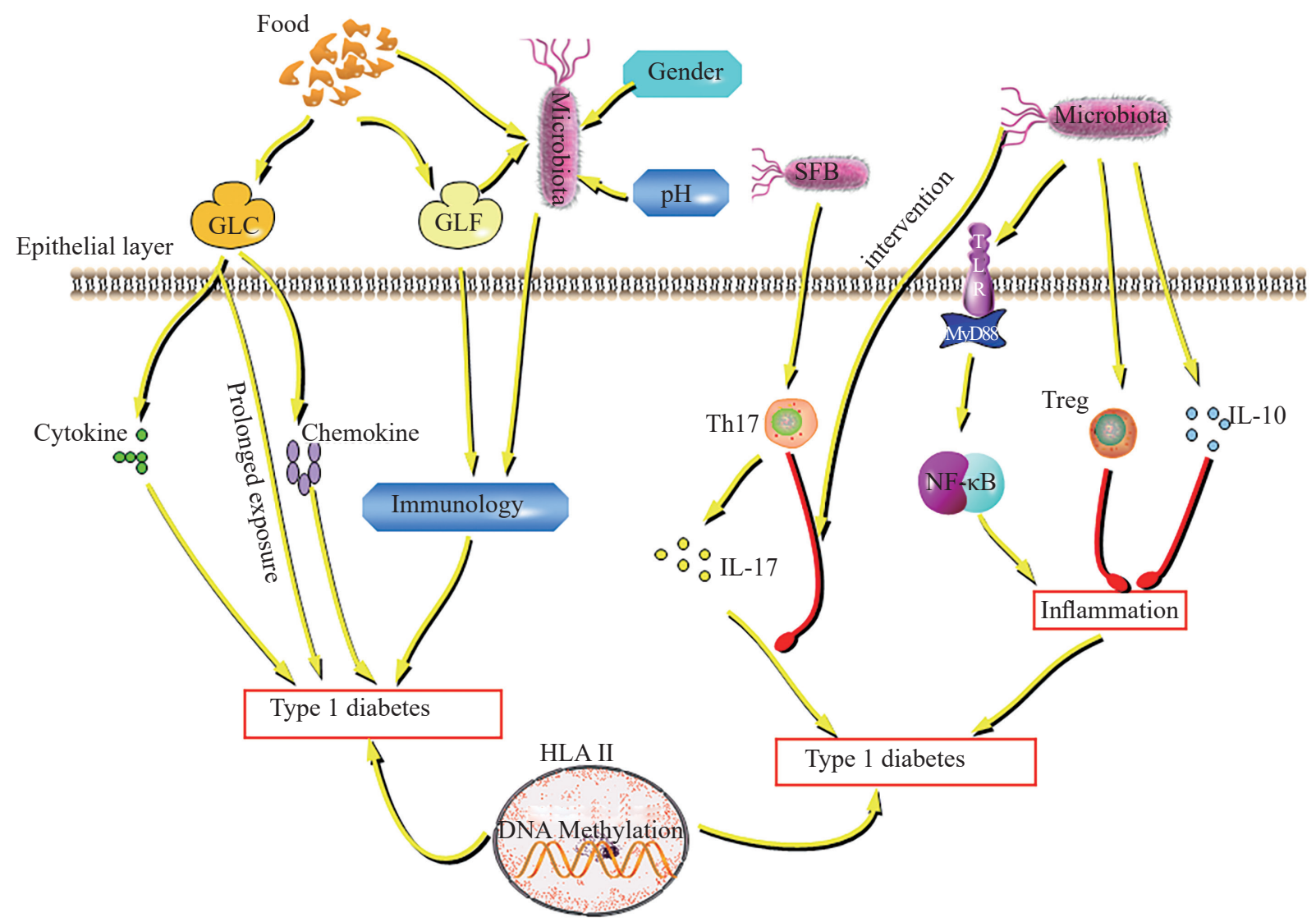

Figure 1 Diagram of the pathogenesis of type 1 diabetes. At the genetic level, type 1 diabetes is related to HLA II genes. Gluten appears to be a dietary determinant of the disease. The GLF diet affects the development of type 1 diabetes by altering the composition and immune function of the gut microbiota. The presence or absence of gluten also appears to affect the onset of diabetes through cytokines/chemokines. In addition, gender and $\mathrm{pH}$ also affect the intestinal flora and are associated with the development of type 1 diabetes. SFB are involved in Th17 cell differentiation, thereby affecting the secretion of IL-17, which may induce type 1 diabetes. However, in the presence of other bacteria, SFB regulate the secretion of IL-17 by Th17 cells and inhibit the development of type 1 diabetes. TLRs recognize MyD88, which activates NF- $\kappa B$ and induces an inflammatory pathway. However, the gut microbiota also promote Treg to release IL-10 to reduce inflammation. 
After the recognition of MyD88 by TLRs, NF-kappaB (NF$\kappa \mathrm{B})$ is activated to induce inflammation. The mechanism(s) underlying the regulation of immunity by intestinal microbiota remain to be elucidated. In a controlled study of 16 children with type 1 diabetes and 16 healthy children, the number of Actinobacteria and Firmicutes, and the ratio of Firmicutes to Bacteroidetes in the type 1 diabetes patients were significantly lower than in healthy children, and the number of Bacteroidetes increased significantly [18]. At the same time, when children developed autoimmune disorders, the number of Firmicutes was reduced and the number of Bacteroidetes was elevated [19]. Thus, changes in microbiota have a causative effect on type 1 diabetes. SFB are also involved in the autoimmune response of type 1 diabetes due to their effects on Th17 and IL-17. When the IL-17 levels are elevated in type 1 diabetes, there are potential pathogenic effects [20]. De Riva and colleagues compared two NOD mouse colonies, NODlow and NODhigh, and found that their cumulative incidences of type 1 diabetes were significantly different [21]. Therefore, SFB apparently inhibits the occurrence of type 1 diabetes through effects on Th17.

The inhibition of type 1 diabetes by SFB in NOD mice may also be related to the effects of other microbiota. Colonization of SFB in Germ-Free GF)-NOD mice did not protect the mice from type 1 diabetes. However, SFB could protect GF mice from type 1 diabetes induced by other symbiotic microbiota [7]. This phenomenon indicates that other bacteria in the intestine have a feedback-regulating effect on SFB-induced type 1 diabetes. Moreover, it was found that the lactic acid bacteria species present in the feces had a negative correlation with the occurrence of type 1 diabetes in a mouse model [22]. The intestinal microbiota also altered the development and function of lymphocytes, wherein the regulatory function of Foxp3 + T cells (Treg) was impaired [23]. However, single colonization of GF mice with bacteriocin can promote the differentiation of Treg and the production of the anti-inflammatory cytokine IL-10 [24].

Molecular mimicry also contributes to the pathogenesis of type 1 diabetes [25]. In view of the wide variety of intestinal microbiota, many bacteria have antigens similar to proteins of the pancreas [26]. For example, the Mgt protein of Leptotrichia goodfellowii and the islet-specific glucose6-phosphatase-related protein (IGRP) have similar peptides. IGRP is a member of the G6Pase family and is specifically expressed in the pancreas [27]. The IGRP206-214 peptide is capable of activating diabetic NY8.3 T cells and inducing diabetes [28]. This phenomenon has also been observed with Enterobacteria. These findings suggest that certain bacteria are present in the gut and can induce or accelerate the development of type 1 diabetes through molecular mimicry. Therefore, the intestinal microbiota is considered to be an important environmental factor affecting the susceptibility to diabetes, and the underlying mechanisms need to be explored.

\section{Links Between Intestinal Microbiota, Obesity and Type 2 Diabetes}

\section{A high-fat diet leads to type 2 diabetes by inducing lipopolysaccharide-rich microbiota}

In the past few decades, there has been an exponential growth of obesity and the associated metabolic syndrome and diabetes, leading researchers to pay increasing attention to the underlying mechanisms. Recent advances in nextgeneration sequencing technology and mechanistic experiments in gnotobiotic mice have confirmed that the intestinal microbiota is an environmental factor leading to obesity [29]. Several theories have been proposed to explain this relationship, and it has been suggested that the intestinal microbiota affect the energy balance, glucose metabolism, and low-grade inflammation, thereby inducing metabolic diseases such as obesity [30]. Compared with the intestinal microbiota of thin mice, Turnbaugh $\mathrm{P}$ et al. observed that the intestinal microbiota transplanted from obese mice was more likely to cause obesity in GF mice [31]. Interestingly, Backhed F et al. found that GF mice fed high-lipid foods gained less weight than conventional mice [32] (Figure 2). Studies have shown that a HFD can induce gut microbiota rich in lipopolysaccharides (LPS), thereby increasing the concentration of LPS in the plasma [33]. LPS is a microbial-associated factor that is continuously produced in the intestine as a result of lysing of Gram-negative bacteria [34]. Of note, Ley RE et al. found that the numbers of Firmicutes (typically Gram-positive) increased and Bacteroidetes (Gram-negative) decreased in obese mice [35]. Although this seems to be a paradox, this increased LPS is directly related to an increase in intestinal permeability, and is characteristic of metabolic endotoxemia. LPS interrupts the intestinal epithelium by inhibiting the expression of tight junction proteins, including zonula occludens-1 (ZO1) and occluding [36]. Muccioli GG et al. found that the endocannabinoid (eCB) system [38] controlled intestinal permeability and lipogenesis. LPS controls adipose tissue metabolism by blocking cannabinoid-driven lipogenesis [38]. This has been postulated to be one of the causes of obesity. The translocation of LPS may be an early cause of insulin resistance [39]. In addition, LPS activates inflammasome proteins in macrophages. It also binds to and activates TLR4, and recruits downstream adapter molecule MyD88 to activate the NF- $\kappa$ B pathway, which ultimately leads to inflammation [40]. In this process, MyD88 binds to the IL-receptor-associated kinase (IRAK1)-tumor necrosis factor receptor-associated factor 6 (TRAF6)-transforming growth factor- $\beta$-activated kinase 1 (TAK1) cascade [41], which mediates TLR4 signaling to NF- $\kappa$ B. Eventually, it leads to the development of low-grade inflammation. TAK1 also interacts with c-Jun NH2-terminal kinase (JNK) [42]. A paper studied the subsequent signaling by JNK [43], and found that inhibition of the pathway could alleviate inflammation and insulin resistance. Among the 
downstream proteins, insulin resistance is mainly induced by the serine phosphorylation of insulin receptor substrate-1 (IRS-1) by JNK [44]. Therefore, IRS-1 phosphorylation by serine is considered to be a marker of insulin resistance. The development of insulin resistance lays the foundation for the development of type 2 diabetes.

\section{Intestinal microbiota regulates short-chain fatty acid} metabolism, improving the resistance to obesity and type 2 diabetes

In addition to the role of LPS, short-chain fatty acids (SCFAs) are another factor related to the development of obesity. The most abundant types of SCFAs are acetate, propionate and butyrate (Figure 2). Acetate and propionate are mainly produced by Bacteroidetes, and butyrate is mainly produced by Firmicutes [45]. Acetate can improve glucose tolerance and butyrate can improve insulin sensitivity and increase energy expenditure in mice, reducing the chance of obesity [46]. In addition, SCFAs regulate energy balance through a number of signaling pathways. SCFAs act as specific ligands for two G-protein coupled receptors (GPR), GPR41 and GPR43 [47], and thereby regulate intestinal epithelial cells. GPR41 is produced by enteroendocrine cells that regulate host energy balance through the gut microbiota. Activation of GPR41 stimulates the production of peptide YY (PYY) [48], which inhibits intestinal movement, and reduces energy extracted from the diet, affecting glucose utilization [49]. Thus, SCFAs enhance satiety and prevent obesity. Kimura et al. demonstrated that SCFAs-mediated GPR43 inhibits insulin signaling in adipocytes and promotes the metabolism of unbound lipids and glucose in other tissues [50]. In addition, SCFAs also activate glucagon-like peptide-1 (GLP-1) via GPR43, resulting in increased insulin sensitivity [51]. These

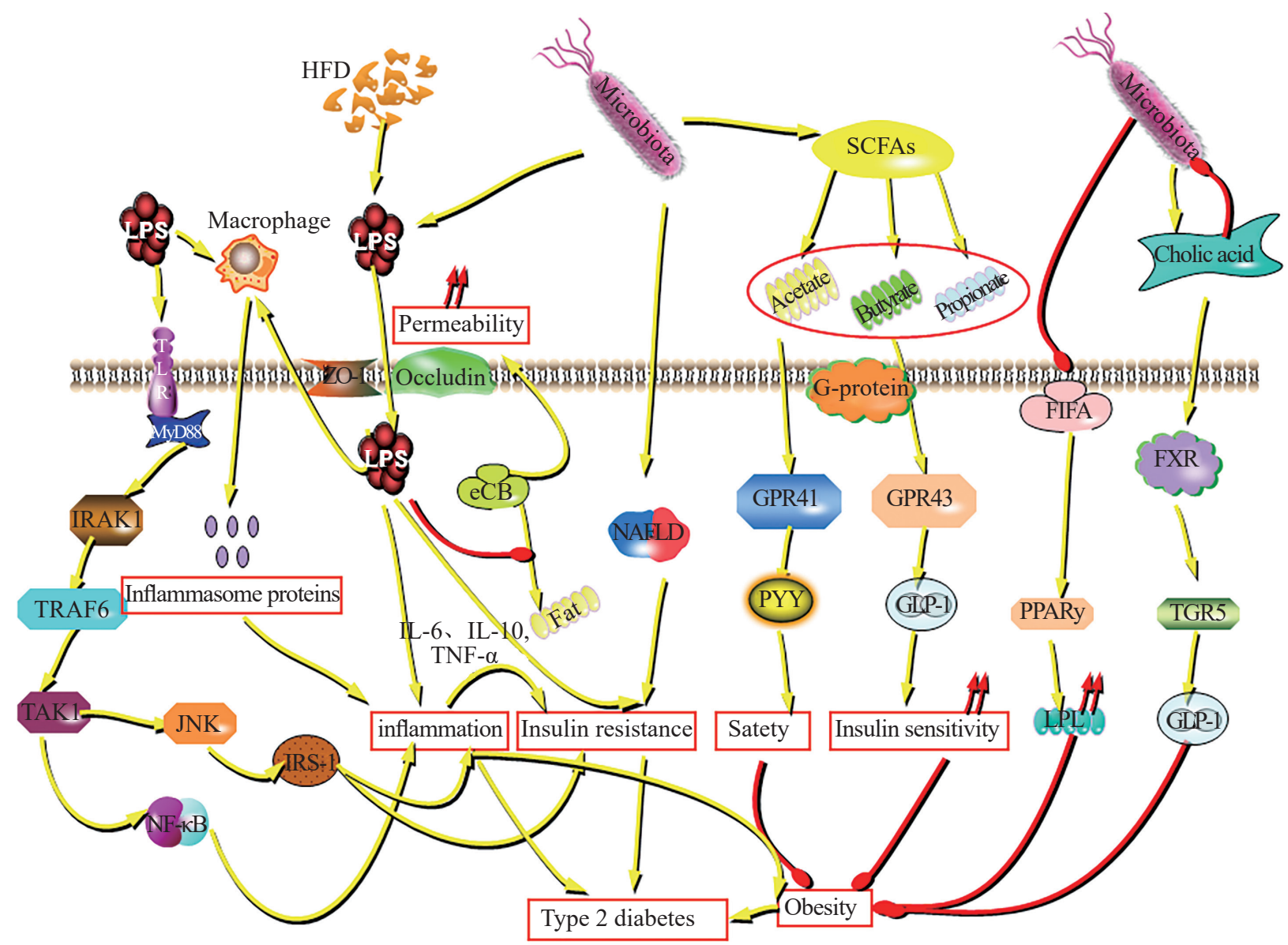

Figure 2 Diagram of the pathogenesis of type 2 diabetes and obesity. A HFD induces LPS-rich intestinal microbiota and increases the concentration of LPS in the plasma. LPS enhances intestinal epithelial cell permeability by destroying ZO-1 and occludin. LPS blocks eCB-mediated regulation of adipose tissue metabolism. The translocation of LPS activates inflammasome proteins in macrophages, inducing inflammation. At the same time, LPS binds to and activates TLR4 and recruits MyD88, activates IRAKTRAF6-TAK1, and initiates signaling via the NF- $\mathrm{B}$ pathway, which ultimately leads to inflammation. TAK1 also interacts with JNK, which induces inflammation and insulin resistance under the induction of IRS-1. In addition to LPS, SCFAs bind to GPR41 and GPR43. GPR41 induces PYY to enhance satiety and prevent obesity. The activation of GLP-1 by GPR43 results in an increase in insulin sensitivity. Microbiota inhibits FIAF and enhances LPL activity, reducing the development of obesity. The intestinal microbiota interacts with bile acids to bind FXR to TGR5 and activate GLP-1 to prevent diet-induced obesity, and thereby type 2 diabetes. 
findings establish GPR43 as a sensor for excess dietary energy, which controls the utilization of body energy while maintaining metabolic balance. Some studies have also shown that GPR43 can enhance insulin sensitivity and inhibit inflammation [52], thus preventing the development of type 2 diabetes.

\section{Intestinal microbiota inhibits fasting-induced adipocyte factor and participates in bile acid metabolism to reduce obesity and type 2 diabetes}

One of the key mechanisms by which GF animals are not affected by diet-induced obesity is the presence of fasting-induced adipocyte factor (FIAF) [53]. FIAF is produced by intestinal epithelial cells and hepatocytes, and can inhibit the activity of lipoprotein lipase (LPL), leading to the accumulation of fat [54] (Figure 2). The intestinal microbiota can inhibit FIAF and enhance the activity of LPL [55]. In mice lacking the FIAF gene, LPL is more active, resulting in a $60 \%$ higher fat content compared to GF mice expressing the FIAF gene [56]. Therefore, FIAF participates in the regulation of intestinal microbiotamediated fat storage. Alex et al. demonstrated that SCFAs induced FIAF by activating the nuclear receptor peroxisome proliferator activated receptor $\gamma(\operatorname{PPAR} \gamma)$ [57]. LPL is then further activated to inhibit the development of obesity.

Cholic acid and deoxycholic acid are the main bile acids synthesized from cholesterol in the human liver. Intestinal bacteria can convert primary bile acids into secondary bile acids [58] (Figure 2). In turn, the antibacterial activity of bile acids helps to inhibit the colonization and growth of microbiota in the gut. Studies have shown that the bacteriostatic action of bile acids mainly occurs through damage to the cell membrane [59]. In this process, primary bile acids activate the nuclear farnesoid $X$ receptor (FXR), which binds to GPR TGR5. The TGR5 signal activates GLP-1 secretion and prevents diet-induced obesity [60]. Intestinal microbiota regulates human metabolism and influences obesity through LPS, SCFAs, FIFA and bile acids.

Researchers also found that a common feature of obesity and type 2 diabetes was the presence of lowgrade inflammation in metabolic tissues [61]. Metabolic inflammation is characterized by the production of cytokines, including IL-6, IL- 1 , and tumor necrosis factor- $\alpha$ $(\mathrm{TNF}-\alpha)$, all of which contribute to insulin resistance and diabetes [62]. Obesity may be the starting point of the lowgrade inflammation. Studies have shown that gut microbiota may play an important role in type 2 diabetes by affecting body weight, SCFAs, pro-inflammatory activity, nonalcoholic fatty liver disease (NAFLD), insulin resistance, and by regulating gut hormones [63]. The induction of LPS by HFD can be demonstrated by injecting LPS into mice being fed a normal diet, which causes hepatic insulin resistance, glucose intolerance, and an increase in adipose tissue weight, which may eventually lead to type 2 diabetes
[64]. SCFAs have significant anti-inflammatory activity, and GPR43 activates GLP-1 to increase insulin sensitivity [65]. NAFLD is a family of liver diseases, including steatosis, fibrosis and cirrhosis, which are associated with obesity, insulin resistance, and diabetes [66]. In terms of fatty acid metabolism, bile acids activate the FXR-TGR5GLP-1 pathway to prevent obesity [67]. This reduces the formation of type 2 diabetes to some extent. However, the role of microbiota in the pathways is not yet clear, and the underlying mechanisms need to be evaluated.

\section{Treatment Strategy}

Probiotics have been gaining increasing attention for the treatment of a variety of diseases [68]. When the host is given a sufficient number of probiotics, the probiotics have a beneficial effect on the host. However, the effects of different bacteria differ, and it is important to select the appropriate combination of bacteria to supplement [69]. A number of studies have shown that probiotic strains, particularly Lactobacillus and Bifidobacteria, have multiple beneficial effects on metabolic syndrome [70]. They can effectively reduce the incidence of both type 1 and type 2 diabetes, improving the quality of life for patients. They appear to promote weight loss and visceral fat reduction, improve glucose tolerance, and regulate intestinal inflammation [71] (Figure 3). Lactobacillus is involved in the metabolism and have demonstrated a number of beneficial effects, including reductions in the fat cell size and overall body fat [72]. Diet-induced obese mice showed a reversal of weight gain after being fed a particular lactobacillus [73]. Lactobacillus can reduce the intestinal mucosal permeability and improve the epithelial barrier function. They slow the progression of type 1 diabetes by inhibiting pro-inflammatory cytokines and inflammatory cytokines, and increasing IL-10 production. At the same time, these bacteria have also been shown to reduce LPSinduced vasomotor dysfunction to reduce inflammatory conditions and islet cell dysfunction [74].

Studies have shown that the beneficial effects of probiotic intervention on glucose tolerance and insulin sensitivity are associated with elevated levels of GLP-1[75]. Lactobacillus can stimulate the production of GLP-1 and serve as a carrier for GLP-1, thereby exerting significant insulinotropic effects in vivo [76]. Due to all of these beneficial effects, Lactobacillus eventually possess antidiabetic effects. An et al. found that bifidobacteria isolated from healthy Korean obese rats had anti-obesity and lipidlowering effects in rats with obesity induced by a high-fat diet [77]. The bifidobacteria promoted the production of GLP-1 and peptide YY and led to the reduction of ghrelin [78] by regulating food intake. Further, Bifidobacterium can prevent diabetes by inhibiting bacterial blood transfer and adhesion to adipose tissue [79]. The oral administration of bifidobacteria increased the expression of insulin receptor $\beta$ (IR $\beta)$, IRS1, protein kinase B (PKB), I $\mathrm{B} B$ kinase $\alpha(\mathrm{IKK} \alpha)$ 
and nuclear factor-kappa B inhibitor $\alpha(\mathrm{I} \kappa \mathrm{B} \alpha)$ protein, and decreased the blood glucose levels significantly [80].

Extracellular-signal regulated kinase (ERK) is a protease involved in the regulation of cell proliferation and differentiation. Alteration of the insulin receptor subtype activates the ERK pathway and is associated with abnormal proliferation and differentiation of intestinal epithelial cells in diabetic mice [81]. Probiotics such as bifidobacteria are involved in regulating the ERK pathway, increasing insulin sensitivity and resisting the onset of diabetes. In addition, in some studies, the effects of probiotics on diabetes were associated with increased levels of SCFAs, particularly butyrate in the colon. SCFAs may be a key component in the growth of lactobacilli and bifidobacteria and in reducing the intestinal $\mathrm{pH}$, all of which are expected to have beneficial effects on diabetes [82]. Probiotics also reduce the storage of fatty acids and facilitate weight loss [83]. In addition, probiotics reduce inflammation by improving the intestinal barrier integrity and reducing the release of proinflammatory cytokines, thereby increasing the glucose alcohol content and insulin sensitivity [84]. This can reduce the incidence of diabetes.

Recently, research on fecal microbiota transplantation (FMT) has attracted great interest. FMT has proven to be a successful method of treating recurrent Clostridium difficile infection (CDI) [85]. The FMT controls human gastrointestinal microbiota by transferring healthy donor microbiota into an existing disrupted microbial ecosystem. The effects are superior to those of antibiotics [86]. Although FMT has been in use for more than 50 years, it has recently gained new momentum. Turnbaugh PJ and colleagues completed a more in-depth study that transplanted the fecal microbiota from obese C57Bl/6J donors into GF-C57B1/6J receptors. The GF mice showed a significant increase in their total body fat compared with the GF mice transplanted with the microbiota of lean mice [87]. In 2012, Vrieze A et al. studied the effects of FMT on insulin sensitivity in patients with metabolic syndrome. Patients with metabolic syndrome were randomly assigned to receive allogeneic or autologous microbiota. A significant increase in insulin sensitivity was observed in patients who were given microbial groups from lean donors [88]. Therefore, gut

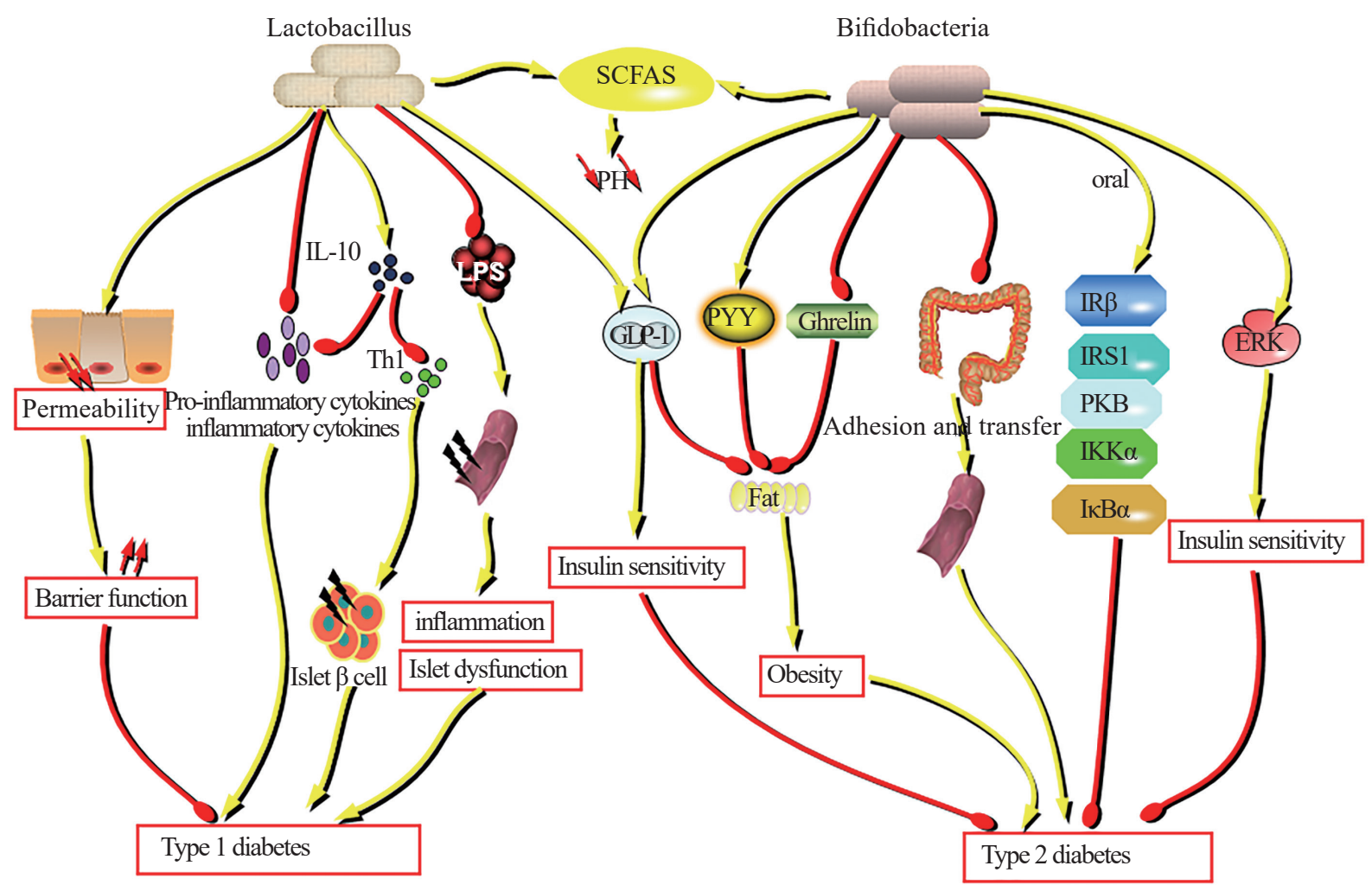

Figure 3 Probiotics play an active role in anti-diabetes strategies. Lactobacillus improves the epithelial barrier function by reducing the intestinal mucosal permeability. Lactobacillus can inhibit pro-inflammatory or inflammatory factors to reduce the development of type 1 diabetes. Lactobacillus prevents the destruction of islet $\beta$ cells by inhibiting Th1 via IL-10. Lactobacillus can reduce LPS-induced vasomotor dysfunction, thereby reducing inflammation status and islet cell dysfunction. Lactobacillus also stimulates the production of GLP-1 and achieves significant insulinotropic effects in vivo. Bifidobacteria promote the production of GLP-1 and PYY and the reduction of ghrelin, inhibiting fat formation. Bifidobacteria inhibit the production of type 2 diabetes by preventing the adhesion and transfer of microbiota. Patients can also increase the expression of IR $\beta, \operatorname{IRS} 1, \mathrm{PKB}, \mathrm{IKK} \alpha$, and IKB $\alpha$ by oral administration of bifidobacteria for therapeutic purposes. Bifidobacteria also participate in the regulation of the ERK pathway, increasing insulin sensitivity and resisting the onset of diabetes. SCFAs are also a key component in the growth of lactobacillus and bifidobacteria and in reducing the intestinal $\mathrm{pH}$, which are all effects expected to be beneficial for diabetes. 
microbiota can act as a synergist to increase the body's sensitivity to insulin, improving obesity and diabetes [89] (Figure 4). These findings have led to an interest in FMT for the treatment of other metabolic syndromes [90]. Although the causal relationship between gut microbiota and various diseases still needs to be confirmed, FMT may prove to be a powerful tool to provide diagnostic and therapeutic clues. In general, differences in the microbiota at the level of major phyla are not specifically related to disease. Studies of the intestinal microbiota should focus on deeper levels of classification or changes in intestinal microbial metabolites [91]. This should be a major direction for future research on FMT.

\section{Impact of abdominal surgery on the microbiota}

In addition to FMT, Roux-en-Y gastric bypass (RYGB) has also received much attention for the management of obesity and diabetes. RYGB results in a significant reduction of approximately $65 \% \sim 75 \%$ of excess body weight and fat mass. This method not only causes a reduction in caloric intake or absorption, but also causes significant changes to the intestinal microbiota [92]. Chen $\mathrm{H}$ et al. first demonstrated that there is a link between changes in gut microbiota and changes in the monocyte phenotype and function after RYGB [93]. This may have an important effect on chronic low-grade inflammation in type 2 diabetes patients. Further, Palleja A et al. found that 3 months after morbidly obese people underwent RYGB, the intestinal microbiota divesity increased, the oxygen tolerance increased, and the potential for nutrient utilization increased [94] (Figure 4). Sleeve gastrectomy (SG), which was developed before RYGB, also has a strong effect on type 2 diabetes and obesity, as well as the microbiota. Murphy et al. found that SG caused an increase in bacteroides while RYGB caused a decrease in the number of Firmicutes and Actinomycetes. However, through a KEGG localization and pathway analysis, the metabolic changes in intestinal microbiota after RYGB treatment were found to be significantly greater than those of intestinal microbiota after SG [95]. Duboc $\mathrm{H}$ et al. compared changes in intestinal microbiotic metabolites after RYGB and $\mathrm{SG}$, and found that the postoperative bile acid production was highly protected by microbiota [96]. In addition, an experiment on the relationship between insulin sensitivity and the bile acids concentration after RYGB revealed that the presence of increased bile acids after metabolic surgery significantly improved insulin sensitivity [97]. These lines of evidence suggest that the intestinal microbiota has some ability to recover and can increase the sensitivity of insulin through alterations in bile acids and the subsequent weight

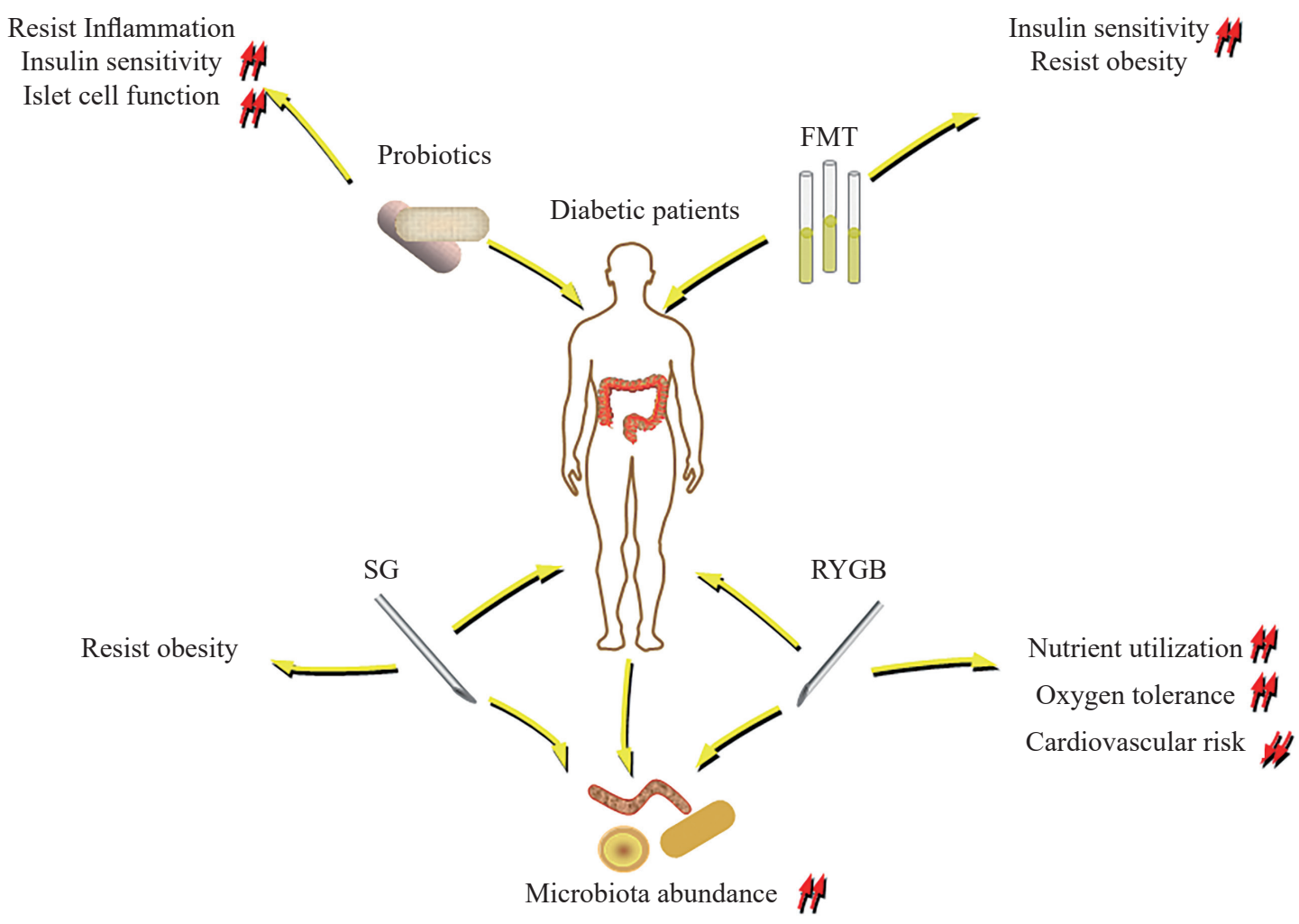

Figure 4 Guidance for the potential use of microbe-related techniques for the clinical treatment of diabetes and obesity. Probiotics treat diabetes by improving resistance to inflammation, increasing insulin sensitivity, and improving the function of islet cells. FMT fights diabetes by resisting obesity and increasing insulin sensitivity. After RYGB, the abundance of microbiota increases. As a result, nutrient utilization increases, oxygen resistance increases, and cardiovascular risk decreases. After SG, the abundance of microbiota is also improved, and the resistance to obesity is enhanced. 
control. At the same time, due to changes in intestinal flow, the reduction of thick-walled bacteria and the increase of Bacteroides are beneficial to the synthesis of vitamin B12 and further increase the weight loss [98]. However, the specific mechanism is still not very clear. Overall, RYGB has more predictable and beneficial changes on the gut microbiota function than SG. In addition, a meta-analysis showed that RYGB was equally as effective as SG in treating diabetes in obese patients, but was associated with a significant reduction in cardiovascular risk [99]. Figure 4 demonstrates the clinical roles of the above techniques. With the help of these microbe-related technologies, the rates of diabetes and obesity will be greatly improved.

\section{Outlook}

In recent years, it has become clear that the intestinal microbiota is important in diabetes and obesity. Disturbances in the intestinal microbiota can damage pancreatic $\beta$ cells and can also lead to obesity and diabetes. It has been found from experimental studies and clinical trials that probiotics may be effective in preventing and managing diabetes and obesity. In addition, diabetes and obesity can be effectively treated by interventions such as FMT, RYGB and SG. The results discussed in this paper are intended to illuminate the pathogenic roles of the gut microbiota in type 1 diabetes, type 2 diabetes, and obesity, and also to guide microberelated pathways to improve diabetes and obesity. We hope that new insights into these pathways will be beneficial to the prevention and treatment of diabetes

\section{Acknowledgments}

We thank Han Jian Zhu and Jin Gao for their technical assistance.

\section{Conflict of interest}

The authors declare that there is no Conflict of interest.

\section{Funding}

This research was funded by the National Natural Science Funding of China (81572344), the Training Project of Key Talents of Youth Medicine in Jiangsu Province, China (QNRC2016330), the Key Disease Standardization Diagnosis and Treatment Project in Jiangsu Province (BE2015664), the Academic Science and Technology Innovation Fund for College Students (x20180714), the Social Development - Health Care Project of Yangzhou, Jiangsu Province, (YZ2018087) and the High-level Talent "Six One Projects" Top Talent Scientific Research Project of Jiangsu Province (LGY2019034).

\section{References}

1. Ma RCW. Epidemiology of diabetes and diabetic complications in China. Diabetologia 2018;61(6):1249-60.

2. Nguyen-Tu M, Nivoit P, Oréa V, et al. Inflammation-linked adaptations in dermal microvascular reactivity accompany the development of obesity and type 2 diabetes. Int J Obes 2019;43,556-66.

3. Bernalier-Donadille A. Fermentative metabolism by the human gut microbiota. Gastroenterol Clin Biol 2010;34 Suppl 1:S16-22.

4. Cani PD, Delzenne NM. Involvement of the gut microbiota in the development of low grade inflammation associated with obesity: focus on this neglected partner. Acta Gastroenterol Belg 2010, 73(2): 267-9.

5. Cepek P, Zajacova M, Kotrbova-Kozak A, Silhova E, Cerna M. DNA methylation and mRNA expression of HLA-DQA1 alleles in type 1 diabetes mellitus. Immunology 2016;148(2):150-9.

6. Nielsen DS, Krych L, Buschard K, Hansen CH, Hansen AK. Beyond genetics. Influence of dietary factors and gut microbiota on type 1 diabetes. FEBS Lett 2014;588(22):4234-43.

7. Kriegel MA, Sefik E, Hill JA, Wu HJ, Benoist C, Mathis D. Naturally transmitted segmented filamentous bacteria segregate with diabetes protection in nonobese diabetic mice. Proc Natl Acad Sci U S A 2011; 108(28):11548-53.

8. Wen L, Ley RE, Volchkov PY, Stranges PB, Avanesyan L, Stonebraker AC, Hu C, Wong FS, Szot GL, Bluestone JA, Gordon JI, Chervonsky AV. Innate immunity and intestinal microbiota in the development of Type 1 diabetes. Nature 2008;455(7216):1109-13.

9. Uy N, Graf L, Lemley KV, Kaskel F. Effects of gluten-free, dairyfree diet on childhood nephrotic syndrome and gut microbiota. Pediatr Res 2015;77(1-2):252-5.

10. Marietta EV, Gomez AM, Yeoman C, Tilahun AY, Clark CR, Luckey DH, Murray JA, White BA, Kudva YC, Rajagopalan G. Low incidence of spontaneous type 1 diabetes in non-obese diabetic mice raised on gluten-free diets is associated with changes in the intestinal microbiome. PLoS One 2013;8(11):e78687.

11. Antvorskov JC, Josefsen K, Engkilde K, Funda DP, Buschard K. Dietary gluten and the development of type 1 diabetes. Diabetologia 2014;57(9):1770-80.

12. Frisk G, Hansson T, Dahlbom I, Tuvemo T. A unifying hypothesis on the development of type 1 diabetes and celiac disease: gluten consumption may be a shared causative factor. Med Hypotheses 2008;70(6):1207-9.

13. Pascale A, Marchesi N, Govoni S, Coppola A, Gazzaruso C. The role of gut microbiota in obesity, diabetes mellitus, and effect of metformin: new insights into old diseases. Curr Opin Pharmacol 2019;49:1-5.

14. Sofi MH, Gudi R, Karumuthil-Melethil S, Perez N, Johnson BM, Vasu C. $\mathrm{pH}$ of drinking water influences the composition of gut microbiome and type 1 diabetes incidence. Diabetes 2014;63(2):632-44.

15. Markle JG, Frank DN, Mortin-Toth S, Robertson CE, Feazel LM, Rolle-Kampczyk U, von Bergen M, McCoy KD, Macpherson AJ, Danska JS. Sex differences in the gut microbiome drive hormone-dependent regulation of autoimmunity. Science 2013;339(6123):1084-8.

16. Stewart CJ, Ajami NJ, O’Brien JL, Hutchinson DS, Smith DP, Wong MC, Ross MC, Lloyd RE, Doddapaneni H, Metcalf GA, Muzny D, Gibbs RA, Vatanen T, Huttenhower C, Xavier RJ, Rewers M, Hagopian W, Toppari J, Ziegler AG, She JX, Akolkar B, Lernmark A, Hyoty H, Vehik K, Krischer JP, Petrosino JF. Temporal development of the gut microbiome in early childhood from the TEDDY study. Nature 2018;562(7728):583-8.

17. Bollyky PL, Bice JB, Sweet IR, Falk BA, Gebe JA, Clark AE, Gersuk VH, Aderem A, Hawn TR, Nepom GT. The toll-like receptor sig- 
naling molecule Myd88 contributes to pancreatic beta-cell homeostasis in response to injury. PLoS One 2009;4(4):e5063.

18. Murri M, Leiva I, Gomez-Zumaquero JM, Tinahones FJ, Cardona F, Soriguer F, Queipo-Ortuno MI. Gut microbiota in children with type 1 diabetes differs from that in healthy children: a case-control study. BMC Med 2013;11:46.

19. Giongo A, Gano KA, Crabb DB, Mukherjee N, Novelo LL, Casella G, Drew JC, Ilonen J, Knip M, Hyoty H, Veijola R, Simell T, Simell O, Neu J, Wasserfall CH, Schatz D, Atkinson MA, Triplett EW. Toward defining the autoimmune microbiome for type 1 diabetes. ISME J 2011;5(1):82-91.

20. Zheng Z, Zheng F. A complex auxiliary: IL-17/Th17 signaling during type 1 diabetes progression. Mol Immunol 2019;105:16-31.

21. De Riva A, Wallberg M, Ronchi F, Coulson R, Sage A, Thorne L, Goodfellow I, McCoy KD, Azuma M, Cooke A, Busch R. Regulation of type 1 diabetes development and B-cell activation in nonobese diabetic mice by early life exposure to a diabetogenic environment. PLoS One 2017;12(8):e0181964.

22. Valladares R, Sankar D, Li N, Williams E, Lai KK, Abdelgeliel AS, Gonzalez CF, Wasserfall CH, Larkin J, Schatz D, Atkinson MA, Triplett EW, Neu J, Lorca GL. Lactobacillus johnsonii N6.2 mitigates the development of type 1 diabetes in BB-DP rats. PLoS One 2010;5(5):e10507.

23. Round JL, Mazmanian SK. Inducible Foxp3+ regulatory T-cell development by a commensal bacterium of the intestinal microbiota. Proc Natl Acad Sci U S A 2010;107(27):12204-9.

24. Round JL, Mazmanian SK. The gut microbiota shapes intestinal immune responses during health and disease. Nat Rev Immunol 2009;9(5):313-23.

25. Siljander H, Honkanen J, Knip M. Microbiome and type 1 diabetes. EBioMedicine 2019;46:512-21.

26. Jarchum I, Nichol L, Trucco M, Santamaria P, DiLorenzo TP. Identification of novel IGRP epitopes targeted in type 1 diabetes patients. Clin Immunol 2008;127(3):359-65.

27. Han B, Serra P, Amrani A, Yamanouchi J, Maree AF, Edelstein-Keshet L, Santamaria P. Prevention of diabetes by manipulation of anti-IGRP autoimmunity: high efficiency of a low-affinity peptide. Nat Med 2005;11(6):645-52.

28. Wang J, Tsai S, Han B, Tailor P, Santamaria P. Autoantigen recognition is required for recruitment of IGRP(206-214)-autoreactive CD8+ T cells but is dispensable for tolerance. J Immunol 2012;189(6):2975-84.

29. Backhed F. Programming of host metabolism by the gut microbiota. Ann Nutr Metab 2011;58 Suppl 2:44-52.

30. Pothuraju R, Sharma RK. Interplay of gut microbiota, probiotics in obesity: a review. Endocr Metab Immune Disord Drug Targets 2018;18(3):212-20.

31. Turnbaugh PJ, Ley RE, Hamady M, Fraser-Liggett CM, Knight R, Gordon JI. The human microbiome project. Nature 2007;449(7164): 804-10.

32. Backhed F, Ding H, Wang T, Hooper LV, Koh GY, Nagy A, Semenkovich CF, Gordon JI. The gut microbiota as an environmental factor that regulates fat storage. Proc Natl Acad Sci U S A 2004;101(44): 15718-23.

33. Cani PD, Bibiloni R, Knauf C, Waget A, Neyrinck AM, Delzenne NM, Burcelin R. Changes in gut microbiota control metabolic endotox- emia-induced inflammation in high-fat diet-induced obesity and diabetes in mice. Diabetes 2008;57(6):1470-81.

34. Ronco C. Lipopolysaccharide (LPS) from the cellular wall of Gram-negative bacteria, also known as endotoxin, is a key molecule in the pathogenesis of sepsis and septic shock. Preface. Blood Purif 2014;37 Suppl 1: 1

35. Ley RE, Backhed F, Turnbaugh P, Lozupone CA, Knight RD, Gordon JI. Obesity alters gut microbial ecology. Proc Natl Acad Sci U S A 2005;102(31):11070-5.

36. Qin LH, Huang W, Mo XA, Chen YL, Wu XH. LPS Induces Occludin Dysregulation in Cerebral Microvascular Endothelial Cells via MAPK Signaling and Augmenting MMP-2 Levels. Oxid Med Cell Longev 2015;2015:120641.

37. Pagotto U, Marsicano G, Cota D, Lutz B, Pasquali R. The emerging role of the endocannabinoid system in endocrine regulation and energy balance. Endocr Rev 2006;27(1):73-100.

38. Muccioli GG, Naslain D, Backhed F, Reigstad CS, Lambert DM, Delzenne NM, Cani PD. The endocannabinoid system links gut microbiota to adipogenesis. Mol Syst Biol 2010;6:392.

39. Jung TW, Park HS, Choi GH, Kim D, Lee T. beta-aminoisobutyric acid attenuates LPS-induced inflammation and insulin resistance in adipocytes through AMPK-mediated pathway. J Biomed Sci 2018;25(1):27.

40. Griffin C, Eter L, Lanzetta N, Abrishami S, Varghese M, McKernan K, Muir L, Lane J, Lumeng CN, Singer K. TLR4, TRIF, and MyD88 are essential for myelopoiesis and $\mathrm{CD} 11 \mathrm{c}(+)$ adipose tissue macrophage production in obese mice. J Biol Chem 2018;293(23):8775-86.

41. Ahmad R, Sylvester J, Zafarullah M. MyD88, IRAK1 and TRAF6 knockdown in human chondrocytes inhibits interleukin-1-induced matrix metalloproteinase-13 gene expression and promoter activity by impairing MAP kinase activation. Cell Signal 2007;19(12):2549-57.

42. Zhang B, Li M, Chen L, Yang K, Shan Y, Zhu L, Sun S, Li L, Wang C. The TAK1-JNK cascade is required for IRF3 function in the innate immune response. Cell Res 2009;19(4):412-28.

43. Zhou J, Xu G, Ma S, Li F, Yuan M, Xu H, Huang K. Catalpol ameliorates high-fat diet-induced insulin resistance and adipose tissue inflammation by suppressing the JNK and NF-kappaB pathways. Biochem Biophys Res Commun 2015;467(4):853-8.

44. Mussig K, Fiedler H, Staiger H, Weigert C, Lehmann R, Schleicher ED, Haring HU. Insulin-induced stimulation of JNK and the PI 3-kinase/mTOR pathway leads to phosphorylation of serine 318 of IRS-1 in C2C12 myotubes. Biochem Biophys Res Commun 2005;335(3):81925.

45. Sheridan PO, Martin JC, Lawley TD, Browne HP, Harris HM, Bernalier-Donadille A, Duncan SH, O’Toole PW, Scott KP, Flint HJ. Polysaccharide utilization loci and nutritional specialization in a dominant group of butyrate-producing human colonic Firmicutes. Microb Genom 2016;2(2):e000043.

46. Gao Z, Yin J, Zhang J, Ward RE, Martin RJ, Lefevre M, Cefalu WT, Ye J. Butyrate improves insulin sensitivity and increases energy expenditure in mice. Diabetes 2009;58(7):1509-17.

47. Karaki S, Tazoe H, Hayashi H, Kashiwabara H, Tooyama K, Suzuki Y, Kuwahara A. Expression of the short-chain fatty acid receptor, GPR43, in the human colon. J Mol Histol 2008;39(2):135-42.

48. Larraufie P, Martin-Gallausiaux C, Lapaque N, Dore J, Gribble FM, 
Reimann F, Blottiere HM. SCFAs strongly stimulate PYY production in human enteroendocrine cells. Scientific reports 2018;8(1):74.

49. Samuel BS, Shaito A, Motoike T, Rey FE, Backhed F, Manchester JK, Hammer RE, Williams SC, Crowley J, Yanagisawa M, Gordon JI. Effects of the gut microbiota on host adiposity are modulated by the short-chain fatty-acid binding $G$ protein-coupled receptor, Gpr41. Proc Natl Acad Sci U S A 2008;105(43):16767-72.

50. Kimura I, Ozawa K, Inoue $D$, Imamura $T$, Kimura K, Maeda $T$, Terasawa K, Kashihara D, Hirano K, Tani T, Takahashi T, Miyauchi $\mathrm{S}$, Shioi G, Inoue H, Tsujimoto G. The gut microbiota suppresses insulin-mediated fat accumulation via the short-chain fatty acid receptor GPR43. Nat Commun 2013;4:1829.

51. Nohr MK, Pedersen MH, Gille A, Egerod KL, Engelstoft MS, Husted AS, Sichlau RM, Grunddal KV, Poulsen SS, Han S, Jones RM, Offermanns S, Schwartz TW. GPR41/FFAR3 and GPR43/FFAR2 as cosensors for short-chain fatty acids in enteroendocrine cells vs FFAR3 in enteric neurons and FFAR2 in enteric leukocytes. Endocrinology 2013;154(10):3552-64.

52. Oh DY, Lagakos WS. The role of G-protein-coupled receptors in mediating the effect of fatty acids on inflammation and insulin sensitivity. Curr Opin Clin Nutr Metab Care 2011;14(4):322-7.

53. Backhed F, Manchester JK, Semenkovich CF, Gordon JI. Mechanisms underlying the resistance to diet-induced obesity in germ-free mice. Proc Natl Acad Sci U S A 2007;104(3):979-84.

54. Qiao Y, Sun J, Xia S, Tang X, Shi Y, Le G. Effects of resveratrol on gut microbiota and fat storage in a mouse model with high-fat-induced obesity. Food Funct 2014;5(6):1241-9.

55. Grootaert C, Van de Wiele T, Verstraete W, Bracke M, Vanhoecke B. Angiopoietin-like protein 4: health effects, modulating agents and structure-function relationships. Expert Rev Proteomics 2012;9(2):18199.

56. Aronsson L, Huang $\mathrm{Y}$, Parini $\mathrm{P}$, Korach-Andre M, Hakansson J, Gustafsson JA, Pettersson S, Arulampalam V, Rafter J. Decreased fat storage by Lactobacillus paracasei is associated with increased levels of angiopoietin-like 4 protein (ANGPTL4). PLoS One 2010;5(9).

57. Alex S, Lange K, Amolo T, Grinstead JS, Haakonsson AK, Szalowska E, Koppen A, Mudde K, Haenen D, Al-Lahham S, Roelofsen H, Houtman R, van der Burg B, Mandrup S, Bonvin AM, Kalkhoven E, Muller M, Hooiveld GJ, Kersten S. Short-chain fatty acids stimulate angiopoietin-like 4 synthesis in human colon adenocarcinoma cells by activating peroxisome proliferator-activated receptor gamma. Mol Cell Biol 2013;33(7):1303-16.

58. Bustos AY, Font de Valdez G, Fadda S, Taranto MP. New insights into bacterial bile resistance mechanisms: the role of bile salt hydrolase and its impact on human health. Food Res Int 2018;112:250-62.

59. Kurdi P, Kawanishi K, Mizutani K, Yokota A. Mechanism of growth inhibition by free bile acids in lactobacilli and bifidobacteria. J Bacteriol 2006;188(5):1979-86.

60. Thomas C, Gioiello A, Noriega L, Strehle A, Oury J, Rizzo G, Macchiarulo A, Yamamoto H, Mataki C, Pruzanski M, Pellicciari R, Auwerx J, Schoonjans K. TGR5-mediated bile acid sensing controls glucose homeostasis. Cell Metab 2009;10(3):167-77.

61. Sokolova RN, Yankova RK, Abadjieva TI, Popova TA, Ivanovska MV, Murdjeva MA, Orbetzova MM, Dermendzhiev SM, Pavlova MV. Association between type 2 diabetes, obesity and key immunologi- cal components of ige-mediated inflammation. Folia Med (Plovdiv) 2017;59(2):159-64.

62. Lei X, Seldin MM, Little HC, Choy N, Klonisch T, Wong GW. C1q/TNF-related protein 6 (CTRP6) links obesity to adipose tissue inflammation and insulin resistance. J Biol Chem 2017;292(36):1483650 .

63. O'Rourke RW. Molecular mechanisms of obesity and diabetes: at the intersection of weight regulation, inflammation, and glucose homeostasis. World J Surg 2009;33(10):2007-13.

64. Blasco-Baque V, Serino M, Vergnes JN, Riant E, Loubieres P, Arnal JF, Gourdy P, Sixou M, Burcelin R, Kemoun P. High-fat diet induces periodontitis in mice through lipopolysaccharides (LPS) receptor signaling: protective action of estrogens. PLoS One 2012;7(11):e48220.

65. Vinolo MA, Ferguson GJ, Kulkarni S, Damoulakis G, Anderson K, Bohlooly YM, Stephens L, Hawkins PT, Curi R. SCFAs induce mouse neutrophil chemotaxis through the GPR43 receptor. PLoS One 2011;6(6):e21205.

66. Radaelli MG, Martucci F, Perra S, Accornero S, Castoldi G, Lattuada G, Manzoni G, Perseghin G. NAFLD/NASH in patients with type 2 diabetes and related treatment options. J Endocrinol Invest 2018;41(5):509-21.

67. Noel OF, Still CD, Argyropoulos G, Edwards M, Gerhard GS. Bile acids, FXR, and metabolic effects of bariatric surgery. J Obes 2016;2016:4390254

68. He M, Shi B. Gut microbiota as a potential target of metabolic syndrome: the role of probiotics and prebiotics. Cell Biosci 2017;7:54.

69. Million M, Raoult D. Species and strain specificity of Lactobacillus probiotics effect on weight regulation. Microb Pathog 2013;55:52-4.

70. Mobini R, Tremaroli V, Stahlman M, Karlsson F, Levin M, Ljungberg M, Sohlin M, Berteus Forslund H, Perkins R, Backhed F, Jansson PA. Metabolic effects of Lactobacillus reuteri DSM 17938 in people with type 2 diabetes: a randomized controlled trial. Diabetes Obes Metab 2017;19(4):579-89.

71. Singh S, Sharma RK, Malhotra S, Pothuraju R, Shandilya UK. Lactobacillus rhamnosus NCDC17 ameliorates type-2 diabetes by improving gut function, oxidative stress and inflammation in high-fat-diet fed and streptozotocintreated rats. Benef Microbes 2017;8(2):243-55.

72. Takemura N, Okubo T, Sonoyama K. Lactobacillus plantarum strain No. 14 reduces adipocyte size in mice fed high-fat diet. Exp Biol Med (Maywood) 2010;235(7):849-56.

73. Lee HY, Park JH, Seok SH, Baek MW, Kim DJ, Lee KE, Paek KS, Lee Y, Park JH. Human originated bacteria, Lactobacillus rhamnosus PL60, produce conjugated linoleic acid and show anti-obesity effects in diet-induced obese mice. Biochim Biophys Acta 2006;1761(7):736-44. 74. Gunnett CA, Lund DD, Faraci FM, Heistad DD. Vascular interleukin-10 protects against LPS-induced vasomotor dysfunction. Am J Physiol Heart Circ Physiol 2005;289(2):H624-30.

75. Yadav H, Lee JH, Lloyd J, Walter P, Rane SG. Beneficial metabolic effects of a probiotic via butyrate-induced GLP-1 hormone secretion. J Biol Chem 2013;288(35):25088-97.

76. Lin Y, Krogh-Andersen K, Pelletier J, Marcotte H, Ostenson CG, Hammarstrom L. Oral delivery of pentameric glucagon-like peptide-1 by recombinant Lactobacillus in diabetic rats. PLoS One 2016;11(9):e0162733.

77. An HM, Park SY, Lee DK, Kim JR, Cha MK, Lee SW, Lim HT, 
Kim KJ, Ha NJ. Antiobesity and lipid-lowering effects of Bifidobacterium spp. in high fat diet-induced obese rats. Lipids Health Dis 2011;10:116.

78. Wang Y, Gao L, Yang Z, Chen F, Zhang Y. Effects of probiotics on ghrelin and lungs in children with acute lung injury: a double-blind randomized, controlled trial. Pediatr Pulmonol 2018;53(2):197-203.

79. Candela M, Seibold G, Vitali B, Lachenmaier S, Eikmanns BJ, Brigidi P. Real-time PCR quantification of bacterial adhesion to Caco2 cells: competition between bifidobacteria and enteropathogens. Res Microbiol 2005;156(8):887-95.

80. Le TK, Hosaka T, Nguyen TT, Kassu A, Dang TO, Tran HB, Pham TP, Tran QB, Le TH, Pham XD. Bifidobacterium species lower serum glucose, increase expressions of insulin signaling proteins, and improve adipokine profile in diabetic mice. Biomed Res 2015;36(1):63-70.

81. Ouyang H, Yang HS, Yu T, Shan TD, Li JY, Huang CZ, Zhong W, Xia ZS, Chen QK. MEK/ERK pathway activation by insulin receptor isoform alteration is associated with the abnormal proliferation and differentiation of intestinal epithelial cells in diabetic mice. Mol Cell Biochem 2016;413(1-2):165-78.

82. Beards E, Tuohy K, Gibson G. Bacterial, SCFA and gas profiles of a range of food ingredients following in vitro fermentation by human colonic microbiota. Anaerobe 2010;16(4):420-5.

83. Peluso I, Romanelli L, Palmery M. Interactions between prebiotics, probiotics, polyunsaturated fatty acids and polyphenols: diet or supplementation for metabolic syndrome prevention? Int J Food Sci Nutr 2014;65(3):259-67.

84. Bron PA, Kleerebezem M, Brummer RJ, Cani PD, Mercenier A, MacDonald TT, Garcia-Rodenas CL, Wells JM. Can probiotics modulate human disease by impacting intestinal barrier function? Br J Nutr 2017;117(1):93-107.

85. Bakker GJ, Nieuwdorp M. Fecal microbiota transplantation: therapeutic potential for a multitude of diseases beyond clostridium difficile. Microbiol Spectr 2017;5(4).

86. Lubbert C, Salzberger B, Mossner J. [Fecal microbiota transplantation]. Internist (Berl) 2017;58(5):456-68.

87. Turnbaugh PJ, Ley RE, Mahowald MA, Magrini V, Mardis ER, Gordon JI. An obesity-associated gut microbiome with increased capacity for energy harvest. Nature 2006;444(7122):1027-31.

88. Vrieze A, Van Nood E, Holleman F, Salojarvi J, Kootte RS, Bartelsman JF, Dallinga-Thie GM, Ackermans MT, Serlie MJ, Oozeer R, Derrien M, Druesne A, Van Hylckama Vlieg JE, Bloks VW, Groen AK, Heilig HG, Zoetendal EG, Stroes ES, de Vos WM, Hoekstra JB, Nieuwdorp M. Transfer of intestinal microbiota from lean donors increases insulin sensitivity in individuals with metabolic syndrome. Gastroenterology 2012;143(4):913-6 e917.

89. Kootte RS, Levin E, Salojarvi J, Smits LP, Hartstra AV, Udayappan SD, Hermes G, Bouter KE, Koopen AM, Holst JJ, Knop FK, Blaak EE, Zhao J, Smidt H, Harms AC, Hankemeijer T, Bergman J, Romijn HA, Schaap FG, Olde Damink SWM, Ackermans MT, Dallinga-Thie GM,
Zoetendal E, de Vos WM, Serlie MJ, Stroes ESG, Groen AK, Nieuwdorp M. Improvement of Insulin Sensitivity after Lean Donor Feces in Metabolic Syndrome Is Driven by Baseline Intestinal Microbiota Composition. Cell Metab 2017;26(4):611-9 e616.

90. Kang Y, Cai Y. Gut microbiota and obesity: implications for fecal microbiota transplantation therapy. Hormones (Athens) 2017;16(3):22334.

91. Suez J, Zmora N, Zilberman-Schapira G, Mor U, Dori-Bachash M, Bashiardes S, Zur M, Regev-Lehavi D, Ben-Zeev Brik R, Federici S, Horn M, Cohen Y, Moor AE, Zeevi D, Korem T, Kotler E, Harmelin A, Itzkovitz S, Maharshak N, Shibolet O, Pevsner-Fischer M, Shapiro H, Sharon I, Halpern Z, Segal E, Elinav E. Post-antibiotic gut mucosal microbiome reconstitution is impaired by probiotics and improved by autologous FMT. Cell 2018;174(6):1406-23 e1416.

92. Liu X, Lagoy A, Discenza I, Papineau G, Lewis E, Braden G, Romanelli J, Braun B, Silva JE. Metabolic and neuroendocrine responses to Roux-en-Y gastric bypass. I: energy balance, metabolic changes, and fat loss. J Clin Endocrinol Metab 2012;97(8):E1440-50.

93. Chen H, Qian L, Lv Q, Yu J, Wu W, Qian H. Change in gut microbiota is correlated with alterations in the surface molecule expression of monocytes after Roux-en-Y gastric bypass surgery in obese type 2 diabetic patients. Am J Transl Res 2017;9(3):1243-54.

94. Palleja A, Kashani A, Allin KH, Nielsen T, Zhang C, Li Y, Brach T, Liang S, Feng Q, Jorgensen NB, Bojsen-Moller KN, Dirksen C, Burgdorf KS, Holst JJ, Madsbad S, Wang J, Pedersen O, Hansen T, Arumugam M. Roux-en-Y gastric bypass surgery of morbidly obese patients induces swift and persistent changes of the individual gut microbiota. Genome Med 2016;8(1):67.

95. Murphy R, Tsai P, Jullig M, Liu A, Plank L, Booth M. Differential changes in gut microbiota after gastric bypass and sleeve gastrectomy bariatric surgery vary according to diabetes remission. Obes Surg 2017;27(4):917-25.

96. Duboc H, Nguyen CC, Cavin JB, Ribeiro-Parenti L, Jarry AC, Rainteau D, Humbert L, Coffin B, Le Gall M, Bado A, Sokol H. Rouxen-Y Gastric-Bypass and sleeve gastrectomy induces specific shifts of the gut microbiota without altering the metabolism of bile acids in the intestinal lumen. Int J Obes (Lond) 2019;43(2):428-31.

97. Ahlin S, Cefalu C, Bondia-Pons I, Capristo E, Marini L, Gastaldelli A, Mingrone G, Nolan JJ. Bile acid changes after metabolic surgery are linked to improvement in insulin sensitivity. Br J Surg 2019;106(9):1178-86.

98. Wagner NRF, Zaparolli MR, Cruz MRR, Schieferdecker MEM, Campos ACL. Postoperative changes in intestinal microbiota and use of probiotics in Roux-En-Y gastric bypass and sleeve vertical gastrectomy: an integrative review. Arq Bras Cir Dig 2018;31(4):e1400.

99. Wang MC, Guo XH, Zhang YW, Zhang YL, Zhang HH, Zhang YC. Laparoscopic Roux-en-Y gastric bypass versus sleeve gastrectomy for obese patients with Type 2 diabetes: a meta-analysis of randomized controlled trials. Am Surg 2015;81(2):166-71. 